\title{
Chemical analysis of Greek pollen - Antioxidant, antimicrobial and proteasome activation properties
}

\author{
Konstantia Graikou', Suzanne Kapeta², Nektarios Aligiannis', George Sotiroudis ${ }^{3}$, Niki Chondrogianni², \\ Efstathios Gonos ${ }^{2}$ and loanna Chinou ${ }^{1 *}$
}

\begin{abstract}
Background: Pollen is a bee-product known for its medical properties from ancient times. In our days is increasingly used as health food supplement and especially as a tonic primarily with appeal to the elderly to ameliorate the effects of ageing. In order to evaluate the chemical composition and the biological activity of Greek pollen which has never been studied before, one sample with identified botanical origin from sixteen different common plant taxa of Greece has been evaluated.

Results: Three different extracts of the studied sample of Greek pollen, have been tested, in whether could induce proteasome activities in human fibroblasts. The water extract was found to induce a highly proteasome activity, showing interesting antioxidant properties. Due to this activity the aqueous extract was further subjected to chemical analysis and seven flavonoids have been isolated and identified by modern spectral means. From the methanolic extract, sugars, lipid acids, phenolic acids and their esters have been also identified, which mainly participate to the biosynthetic pathway of pollen phenolics. The total phenolics were estimated with the FolinCiocalteau reagent and the total antioxidant activity was determined by the DPPH method while the extracts and the isolated compounds were also tested for their antimicrobial activity by the dilution technique.
\end{abstract}

Conclusions: The Greek pollen is rich in flavonoids and phenolic acids which indicate the observed free radical scavenging activity, the effects of pollen on human fibroblasts and the interesting antimicrobial profile.

\section{Background}

Bee pollen is a fine powder-like material produced by flowering plants pollen, mixed with nectar and bee secretions [1] and gathered by the honey-bees. Pollens are the male reproductive cells of flowers and bees' primary food source, containing concentrations of phytochemicals and nutrients and rich in secondary metabolites. During ancient times, people throughout the world used pollen for its medical properties as to alleviate or cure conditions such as colds, flu, ulcers, premature ageing, anemia, and colitis [2].

In our days, is increasingly used as health food supplements and is currently marketed widely in Europe and Asia as a tonic primarily with appeal to the elderly to

\footnotetext{
* Correspondence: ichinou@pharm.uoa.gr

'University of Athens, School of Pharmacy, Division of Pharmacognosy and Chemistry of Natural Products, Zografou Campus, 15771, Athens, Greece Full list of author information is available at the end of the article
}

ameliorate the effects of ageing. Moreover, in many recent papers the chemical profile of different bee-pollens has been reported $[3,4]$.

It is known that bee pollen contains lipids, sugars, proteins, amino acids, vitamins, carotenoids, polyphenolics such as flavonoids and carbohydrates [4]. Especially the carbohydrates are derived from the nectar with which the flower pollen has been mixed in the flowers. The phenolic composition of pollen principally consists of flavonol glycosides and of hydroxycinnamic acids [5]. This composition tends to be species-specific [5-8] and has been related to the therapeutic properties (antibiotic, antineoplasic, antidiarrhoeic and antioxidant) of pollen [1,7-9].

In order to evaluate the chemical composition as well as the biological activities of Greek pollen which has never been studied before, one sample with identified botanical origin of sixteen different common taxa of Greek flora has been investigated. 
The proteasome, a non-lysosomal threonine protease, is responsible for the turnover of both normal and damaged intracellular proteins. It has been suggested to serve as a secondary antioxidant mechanism [10]. Once cells are challenged with oxidative stress, the proteasome is activated. It degrades oxidatively and otherwise damaged proteins, thus preventing the formation and accumulation of protein aggregates that in turn have additional deleterious side effects [11]. This complex is critical for the maintenance of cellular viability and may be particularly important for the cell under various conditions of stress, during failure of homeostasis and senescence.

It has been already shown that the proteolytic activities of the proteasome machinery decline during aging in several human tissues as well as in senescent primary cultures [12]. On the other hand, the increased expression of proteasome catalytic subunits leads to increased levels of functional proteasome and in turn, in delay of the appearance of the senescence phenotype. Given the fundamental importance of proteasome function during aging, the aim of this study was to identify natural pollen extracts that induce proteasome activity. A Greek pollen sample was fractionated in three different polarity extracts and their possible proteasome activating properties were tested in human primary fibroblasts. It has been demonstrated that this pollen leads to stimulation of proteasome activities in human fibroblasts. In regard to the different polarity extracts, the water extract was mainly found to induce proteasome activity, thus revealing possible antioxidant properties.

Due to this activity the aqueous extract was selected for further chemical analysis and seven flavonoids have been isolated. Sugars, fatty acids and also phenolic acid and their esters, which mainly participate to the biosynthetic pathway of pollen phenolics, have been also identified from the methanolic and dichloromethane extract. The structural elucidation was determined by modern spectral means 1D- \& 2D-NMR and by GC/MS after sample derivatization. The total phenolics were estimated with the Folin-Ciocalteau reagent and the antioxidant activity was determined by the DPPH method while the extracts due to their chemical consistency (rich in total phenolics) and the isolated compounds were also tested for their antimicrobial activity by the dilution technique against nine microbial strains. To the best of our knowledge neither Greek nor any other pollen has been tested before against human pathogenic bacteria and/or fungi.

\section{Results and discussion Chemical analysis}

To our knowledge, this is the first report on the chemical analysis and biological activities of Greek pollen. The aqueous fractions of the studied pollen material have been shown to contain the flavonoid content of kaempferol 3-O-rhamnoside (1), quercetin 3-O-glucoside (2), quercetin 3-O-galactoside (3), quercetin 3-O-rhamnoside (4), isorhamnetin 3-O-xylosyl(1-6)glucoside (5), 7-Omethylherbacetin 3-O-sophoroside (6), and 7-O-methylherbacetin 3-O-glucosyl-8-O-galactoside (7) (Figure 1). It is noteworthy that all isolated flavonoids are flavonols 3 -glycosides, which as a finding is in accordance with previous studies [6] where it has been proposed that such compounds have shown to act as essential stimulants of pollen tube growth in several flowering plants and as such appear to play a vital role in the plant fertilization process.

A wide range of flavonoid types has been determined previously from pollen samples of different geographic origin among which mainly flavones [13], flavonols [14], dihydroflavonols and chalcones [15]. Benzoic acid derivatives and hydroxycinnamic acids have been also identified from pollen [16]. Flavonoids are widely recognised as reliable chemotaxonomic markers not only of plants but also of bee pollen and honey. The flavonoids in pollen and honey give special information of geographic and botanical origin of the samples $[6,17]$ as the flavonoid pattern of each pollen differentiates, in comparison with pollen originality. It is interesting that Cistus beepollen contains a large number of flavonoids while other pollens previously analysed contained much fewer [17]. Thus, from almond bee-pollen only methoxykaempferol, quercetin and kaempferol 3-sophorosides were detected [18] while rosemary bee-pollen contained only quercetin and kaempferol 3-sophorosides [19]. These very distinctive flavonoid patterns support the use of flavonoid analysis in the studies of the botanical origin of bee pollen [17].

Concerning the studied sample, its microscopical analysis has been resulted to the following 16 different common taxa of the Greek Flora: Papaver rhoeas, Chamomila recutita, Sinapis arvensis, Cistus sp., Trifolium sp., Dorycnium sp., Cichorium sp., Convolvulus sp., Circium sp., Malva sylvestris, Fumaria sp., Eucalyptus camaldulensis, Anemone sp., Ononis sp., Asphodelus sp. and Quercus ilex.

As the Greek studied pollen is a complicated mixture of pellets from sixteen common spring flowering plants, no further correlation between floral origin and structures of isolated compounds can be given.

The methanolic extract was rich in sugars, as well as in fatty acids, fatty acid esters, phenolic acids (p-coumaric acid, ferulic acid, their glycerol esters and glycerol ester of caffeic acid) while the dichloromethane extract afforded fatty acids as linoleic acid, palmitic acid, methyl malonic acid and benzoic acid; fatty acid esters as palmitic acid methyl ester, linoleic acid methyl ester, 


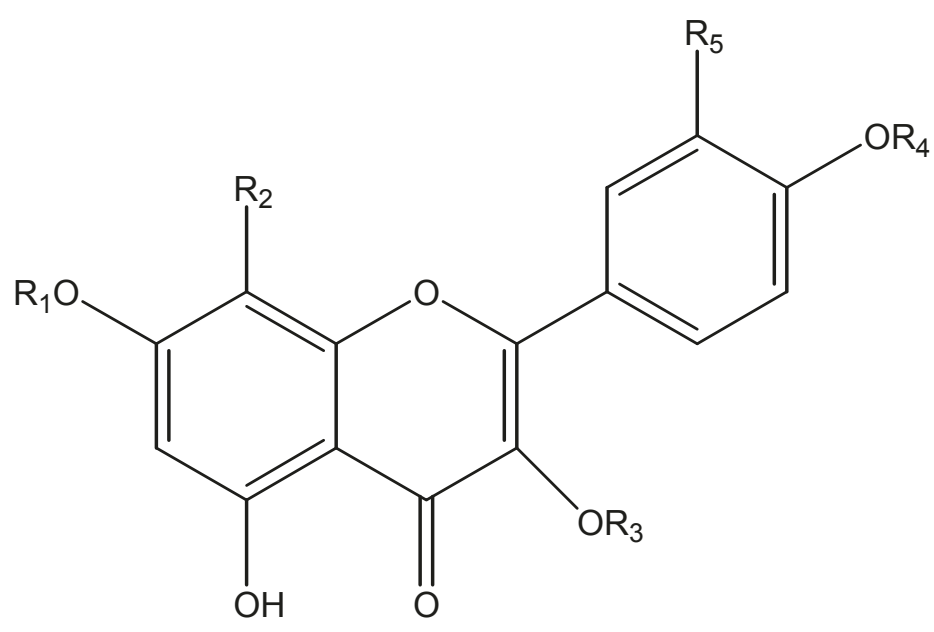

\begin{tabular}{cccccc}
\hline & $\mathbf{R} 1$ & R2 & R3 & R4 & R5 \\
\hline $\mathbf{1}$ & $\mathrm{H}$ & $\mathrm{H}$ & $\alpha$-L-rhamnopyranosyl & $\mathrm{H}$ & $\mathrm{H}$ \\
\hline $\mathbf{2}$ & $\mathrm{H}$ & $\mathrm{H}$ & $\beta$-D-glucopyranosyl & $\mathrm{H}$ & $\mathrm{OH}$ \\
\hline $\mathbf{3}$ & $\mathrm{H}$ & $\mathrm{H}$ & $\beta$-D-galactopyranosyl & $\mathrm{H}$ & $\mathrm{OH}$ \\
\hline $\mathbf{4}$ & $\mathrm{H}$ & $\mathrm{H}$ & $\alpha$-L-rhamnopyranosyl & $\mathrm{H}$ & $\mathrm{OH}$ \\
\hline $\mathbf{5}$ & $\mathrm{H}$ & $\mathrm{H}$ & $\begin{array}{c}\beta \text {-D-Xylopyranosyl }(1-6) \\
\beta \text {-D-glucopyranosyl }\end{array}$ & $\mathrm{H}$ & $\mathrm{OCH}_{3}$ \\
\hline $\mathbf{6}$ & $\mathrm{CH}_{3}$ & $\mathrm{OH}$ & $\begin{array}{c}\beta \text {-D-glucopyranosyl }(1- \\
2) \beta \text {-D-glucopyranosyl }\end{array}$ & $\mathrm{H}$ & $\mathrm{H}$ \\
\hline $\mathbf{7}$ & $\mathrm{CH}_{3}$ & $\beta$-D-galactopyranosyl & $\beta$-D-glucopyranosyl & $\mathrm{H}$ & $\mathrm{H}$ \\
\hline
\end{tabular}

Figure 1 The structures of the isolated flavonoids.

linolenic acid methyl ester, linolenic acid ethyl ester, stearic acid methyl ester, arachidic acid methyl ester, behenic acid methyl ester, as well as methyl palmitate.

According to literature data, it seems that, in general, the dominant fatty acids present in pollens are: palmitic (C-16), oleic (C-18:1), linoleic (C-18:2) and linolenic (C$18: 3)$ acid $[4,20]$. Pollen varies in the relative proportions of fatty acids as well as in their diversity [20,21]. Fatty acids are important in the reproduction, development, and nutrition of honeybees $[20,22]$. Certain fatty acids, such as linoleic, linolenic, myristic and lauric acids, have bactericidal and antifungal properties that are important for colony hygiene $[20,23]$.

The methanolic extract after derivatization was analyzed through GC-MS and it was found rich in sugars, as well as in fatty acids, fatty acid esters, phenolic acids (p-coumaric acid, ferulic acid, their glycerol esters and glycerol ester of caffeic acid). The sugar content of pollen has been also investigated and the presence of a high content of mannitol as well as of glucose, sucrose and fructose has been reported in accordance with previous studies [24].

\section{Proteasome activation mediated by aqueous extract of pollen}

Given that only very few natural compounds and extracts have been shown to activate the proteasome $[25,26]$, we examined the effect of pollen extracts on proteasome activity. HFL-1 cells were treated with different concentrations of the pollen extracts ranging from 0.5 to $10 \mu \mathrm{g} / \mathrm{ml}$ for $24 \mathrm{~h}$ and the CT-L proteasome activity was measured (Figure 2). The aqueous extract exhibited proteasome stimulatory properties. More specifically, CT-L proteasome activity was increased from 1.8 to 2.2 folds at the effective concentrations of 0.5 and $2 \mu \mathrm{g} / \mathrm{ml}$. Moreover we have also detected enhanced protein expression levels of $\beta_{2}$ and $\beta_{5}$ representative proteasome subunits in HFL- 1 cells treated with $0.5 \mu \mathrm{g} / \mathrm{ml}$ of aqueous extract for $24 \mathrm{~h}$ as compared to the $\mathrm{H}_{2} \mathrm{O}$ - treated cultures (control) (Figure 3). The stimulation of proteasome activity by 1.8-2.2 fold is a biologically significant increase that has been shown before by other natural compounds with proteasome activating properties [26]. The effects of such activation are significant given that a $\sim 2$ fold proteasome activation has been 
A.

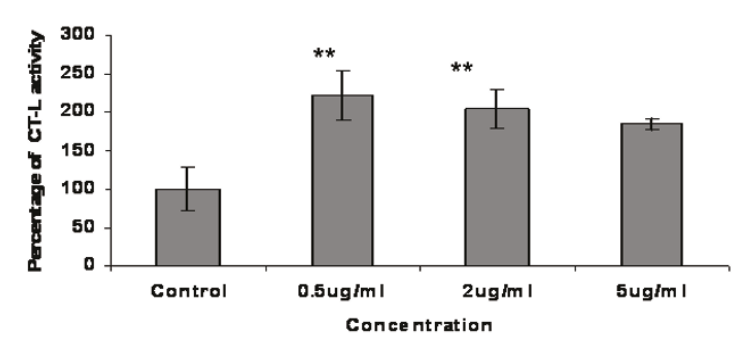

B.

Methanolic extract

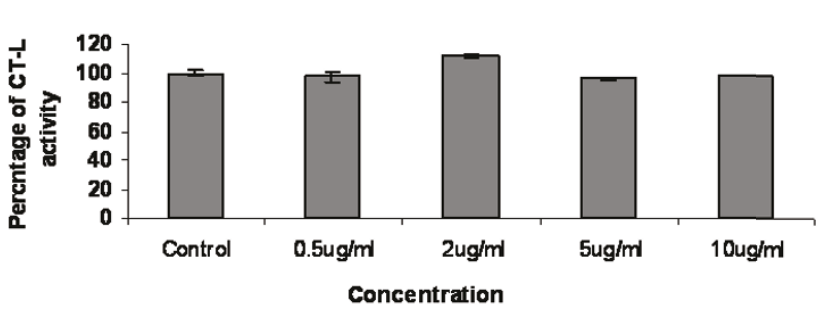

c.

Dichloromethane extract

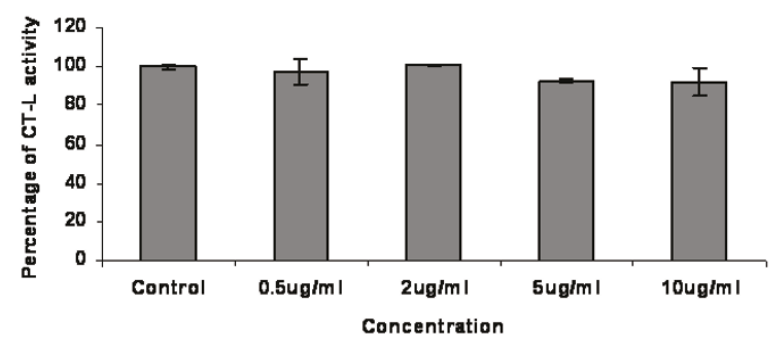

Figure 2 Levels of CT-L proteasome activity. Percentage of CT-L proteasome activity in young HFL-1 cells treated with different concentrations of (A) aqueous, (B) methanolic and (C) dichloromethane extract of pollen for $24 \mathrm{~h}$. Use of proteasome inhibitor (MG132) in control reactions ensured the specificity of the enzymatic reaction. Activities in control cells were arbitrary set to $100 \%$.

shown to confer cytoprotective effects to human fibroblasts against oxidative stress and to extend their cellular lifespan [26].

Proteasome activation by methanolic fraction of aqueous extract fractionation

We then further examined which fraction of the aqueous extract is responsible for the observed proteasome

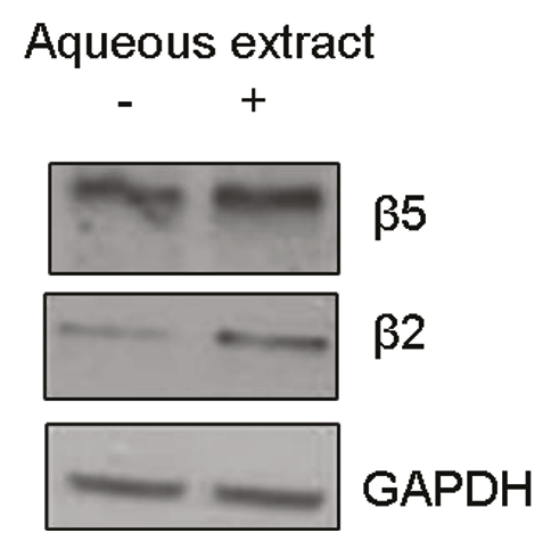

Figure 3 Proteasome activation by the aqueous extract of pollen. Immunoblot analysis of the representative proteasome subunits in HFL-1 cells treated with $0.5 \mu \mathrm{g} / \mathrm{ml}$ of the aqueous extract of pollen for $24 \mathrm{~h}$. GAPDH levels were used as loading control. activation. More specifically, the initial aqueous fraction was further fractionated in aqueous and methanolic fractions. HFL-1 cells were then treated with different concentrations of these fractions ranging from 0,5 to $10 \mu \mathrm{g} /$ $\mathrm{ml}$ for $24 \mathrm{~h}$ and the CT-L proteasome activity was measured (Figure 4). Cell treatment with 0.5 and $2 \mu \mathrm{g} / \mathrm{ml}$ of the methanolic fraction for $24 \mathrm{~h}$ induced the CT-L proteasome activity (Figure 4A) while the aqueous fraction did not promote a similar activation (Figure 4B).

\section{Total phenolics}

Total phenolic compound contents of the methanolic extract was found at the value of $10.49 \pm 0.3 \mathrm{mg}$ of protocatechuic acid equivalents per gram of pollen which is a value generally lower compared to pollen from Brazil or Arizona $[1,9]$.

\section{Radical scavenging activity}

That the flavonoid/phenolic components must play a significant role in the free radical capacity scavenging of bee pollen is indicated by the observation that the pollens which exhibit the highest activity are those that contain the highest level of flavonoids and phenolic acid derivatives [7].

The free radical scavenging activity of the methanolic fraction of the Greek pollen aqueous extract was determined at various pollen extract concentrations and expressed as $E_{50}$ value. BHT, a well known food 

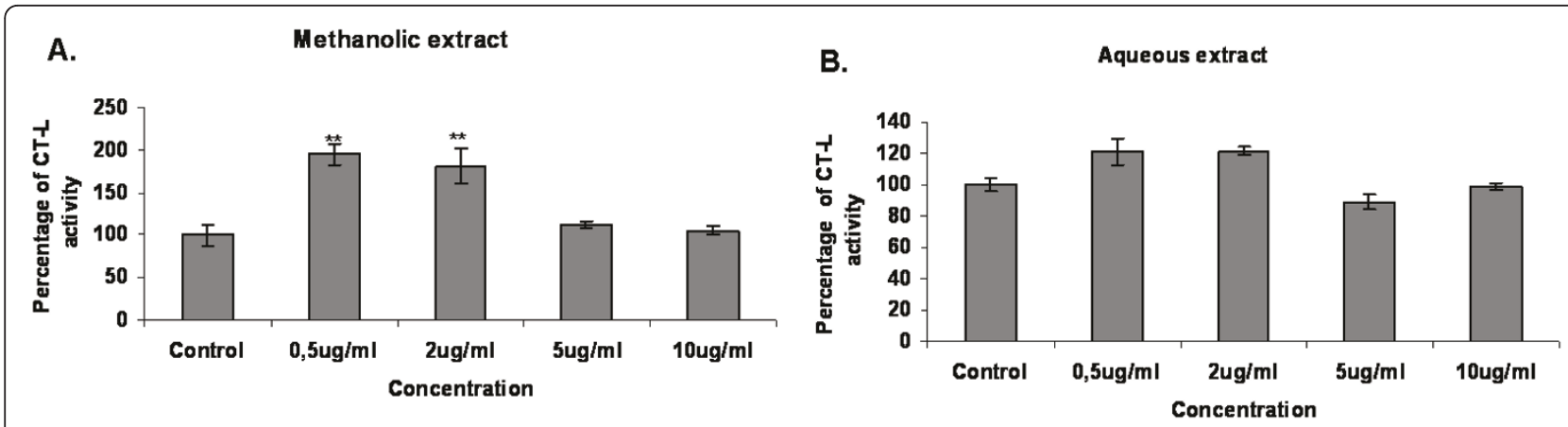

Figure 4 Proteasome activation by the methanolic fraction of the aqueous extract fractionation. Percentage of CT-L proteasome activity in young HFL-1 cells treated with different concentrations of (A) the methanol and (B) the aqueous extract of the aqueous fraction for $24 \mathrm{~h}$. Use of proteasome inhibitor (MG132) in control reactions ensured the specificity of the enzymatic reaction. Activities in control cells were arbitrary set to $100 \%$.

additive antioxidant (E321) [27] was used as standard (Figure 5). The $\mathrm{EC}_{50}$ value calculated for the extract was $181.4 \pm 1.7 \mu \mathrm{g} / \mathrm{mL}$ and is comparable to values acquired for several types of pollen $[1,8,9]$. Specifically, Greek pollen was found to be about 10-fold more active than Brazilian pollen [9] but it was found to vary between slightly less active to almost 10 -fold less active compared to bee pollen from several Arizona plants [1]. It also showed 10 -fold to 30 -fold lower antiradical activity than bee pollen from Mexico [8].

\section{Antimicrobial activity}

The extracts of the studied Greek pollen as well as the isolated flavonoids were evaluated for their antimicrobial activity against six Gram-negative and -positive bacterial strains and three human-pathogenic fungi. The results of these tests (Table 1) showed that the dichloromethane extract expressed a very weak activity while the methanol and aqueous extracts showed an interesting antibacterial activity especially against Gram positive bacteria (MIC values $0.50-0.80 \mathrm{mg} / \mathrm{ml}$ ), and a weaker antifungal activity (MIC values $3.00-5.95 \mathrm{mg} / \mathrm{ml}$ ). The assayed isolated flavonoids showed a comparable antimicrobial profile, with strong activity against Gram-positive bacteria. E. coli, appeared as the most resistant of all assayed bacterial strains for all tested extracts and isolated compounds. The expressed activity of both methanolic and water pollen extracts could be attributed mainly to the high content of flavonoids such as quercetin and kaempferol glucosides which are known to possess antibacterial activity [28]. Moreover, according to literature data, pollen extracts have been assayed very rarely for their antimicrobial activity especially against human pathogenic bacteria and fungi. Among the reported studies, the extract of one Turkish bee-pollen has been reported to possess strong antibacterial activity against plant pathogenic bacteria [29] and a very weaker one against food-related microorganisms [30].

\section{Experimental}

\section{Sample collection}

Bee pollen was collected from the area of Peloponnesus by the end of April 2006 and it was studied microscopically before extraction and analysis.

\section{Pollen chemical analysis}

Bee pollen $(1 \mathrm{~kg})$ was extracted with solvents of increasing polarities and the extracts were concentrated under reduced pressure to give $6.8 \mathrm{~g} \mathrm{CH}_{2} \mathrm{Cl}_{2}$ extract, $301.6 \mathrm{~g}$ $\mathrm{MeOH}$ extract and $244.3 \mathrm{~g} \mathrm{H}_{2} \mathrm{O}$ extract, respectively.

The $\mathrm{CH}_{2} \mathrm{Cl}_{2}$ extract was chromatographed through GC-MS to afford fatty acids as linoleic acid, palmitic acid, methyl malonic acid and benzoic acid; fatty acid esters as palmitic acid methyl ester, linoleic acid methyl ester, linolenic acid methyl ester, linolenic acid ethyl ester, stearic acid methyl ester, arachidic acid methyl ester, behenic acid methyl ester and methyl palmitate.

An aliquot $(2 \mu \mathrm{L})$ of the sample was injected into the gas chromatograph at a split ratio 1:20. The GC-MS analysis was performed using a Hewlett Packard 6890 series II gas chromatograph equipped with an HP-5 capillary column $(30 \mathrm{~m}, 0.25 \mathrm{~mm}$ i.d., $0.25 \mu \mathrm{m}$ film thickness) and a mass spectrometer 5973 of the same company which was operated on EI mode. Helium was the carrier gas at a flow rate of $1 \mathrm{ml} / \mathrm{min}$. For the dichloromethane extract the injector was operated at $200^{\circ} \mathrm{C}$ and the oven temperature was programmed as follows: $60^{\circ} \mathrm{C}$ for $5 \mathrm{~min}$, then gradually increased to $280^{\circ}$ $\mathrm{C}$ with a $3^{\circ} \mathrm{C} / \mathrm{min}$ rate. The identification of the compounds was based on comparison of their retention indices (RI), retention times (RT) and mass spectra with those from Wiley libraries spectra and literature data. 


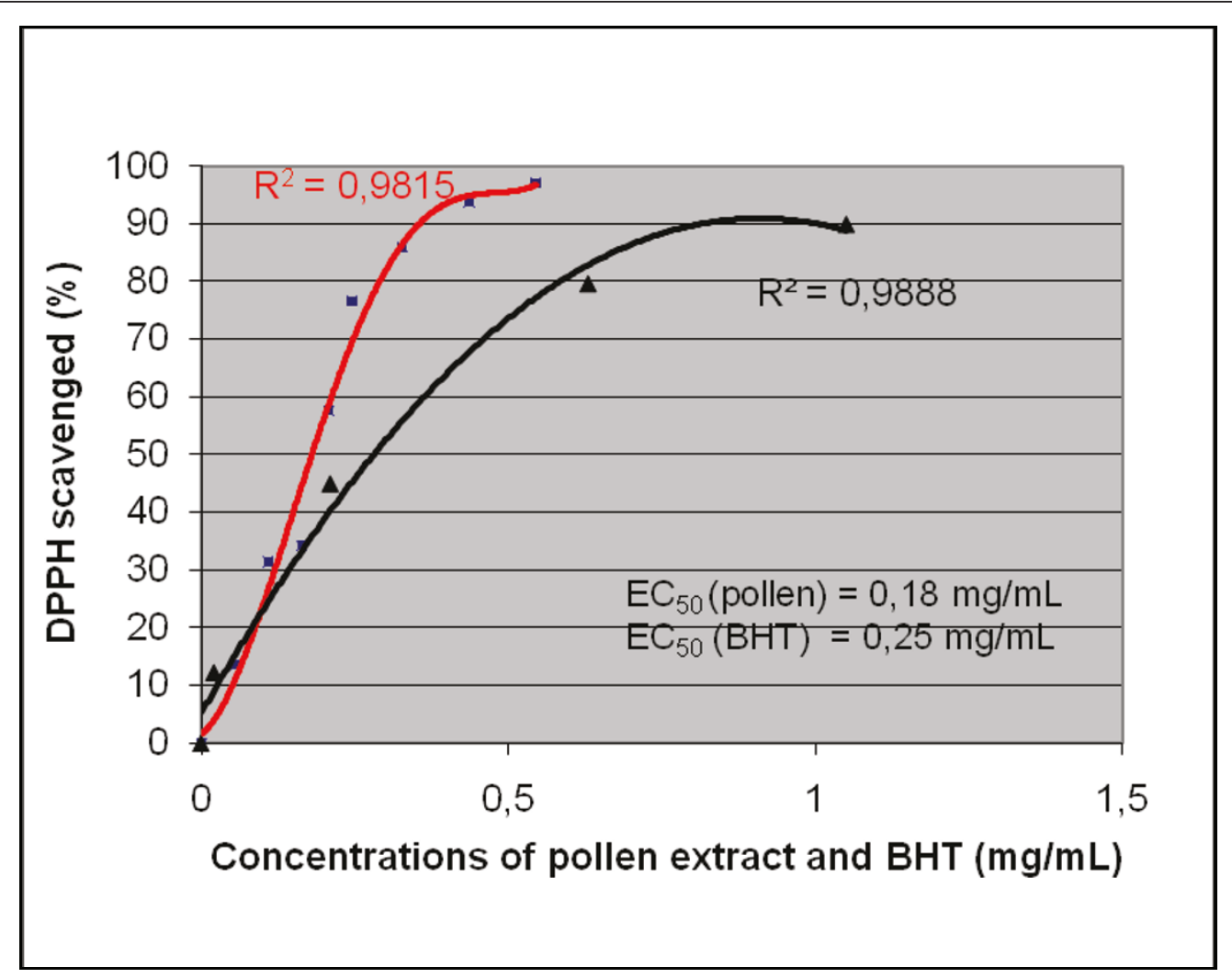

\section{(匹) pollen extract; ( $\boldsymbol{\Delta})$ BHT.}

Figure 5 Effect of the concentration of pollen methanol extract and the standard antioxidant BHT on DPPH radical scavenging. Final DPPH concentration was $66.7 \mu \mathrm{M}$ in all reaction mixtures.

The $\mathrm{MeOH}$ extract was derivatised and chromatographed through GC-MS. It appeared rich in fatty acids and their esters as well as in phenolic acids as cinnamic and ferulic acid and their esters. Furthermore, through this chemical procedure, the major sugars were also determined as D-fructose, sorbose, L-altrose, $\beta$-D-glucopyranose, $\alpha$-Dglucopyranose, D-mannopyranose, D-glucitol, mannitol, melibiose, talose, sucrose, maltose and lactose.

The $\mathrm{H}_{2} \mathrm{O}$ extract was separated through resin (Amberlite $\mathrm{XAD}-4$ ) to the aqueous-aqueous fraction (aq-aq) and

Table 1 Antimicrobial activities (MIC $\mathrm{mg} / \mathrm{ml}$ ) of pollen extracts and their isolated compounds.

\begin{tabular}{|c|c|c|c|c|c|c|c|c|c|}
\hline & S. aureus & S. epidermidis & P. aeruginosa & E. cloacae & K. pneumoniae & E. coli & C. albicans & C. tropicalis & C. glabrata \\
\hline $\mathrm{CH}_{2} \mathrm{Cl}_{2}$ extract & 6.40 & 6.68 & $>10$ & $>10$ & $>10$ & $>10$ & - & - & - \\
\hline $\mathrm{MeOH}$ extract & 0.74 & 0.80 & 2.4 & 2.78 & 3.10 & $>10$ & 5.50 & 4.80 & 4.25 \\
\hline $\mathrm{H}_{2} \mathrm{O}$ extract & 0.50 & 0.62 & 1.35 & 1.46 & 2.50 & $>10$ & 4.81 & 3.00 & 3.22 \\
\hline (1) & 0.88 & 0.70 & 1.69 & 1.77 & 3.22 & 8.89 & 5.95 & 4.78 & 4.80 \\
\hline (2) \& (3) & 0.45 & 0.53 & 1.25 & 1.38 & 3.40 & 7.33 & 7.50 & 6.23 & 5.79 \\
\hline (4) & 0.67 & 0.45 & 1.17 & 1.50 & 2.98 & 3.29 & 6.40 & 5.75 & 5.54 \\
\hline (5) & 0.94 & 0.88 & 1.78 & 1.90 & 2.75 & 7.94 & 4.20 & 4.12 & 3.96 \\
\hline (6) & 0.80 & 0.77 & 2.33 & 2.71 & $>10$ & $>10$ & $>10$ & 6.77 & 6.70 \\
\hline (7) & 0.87 & 0.74 & 1.30 & 2.23 & $>10$ & $>10$ & $>10$ & 5.38 & 5.12 \\
\hline netilmicin & $4 \cdot 10^{-3}$ & $4 \cdot 10^{-3}$ & $8.8 \cdot 10^{-3}$ & $8 \cdot 10^{-3}$ & $8 \cdot 10^{-3}$ & $10 \cdot 10^{-3}$ & - & - & - \\
\hline 5-flucytocine & - & - & - & - & - & - & $0.1 \times 10^{-3}$ & $1 \times 10^{-3}$ & $10 \times 10^{-3}$ \\
\hline itraconazole & - & - & - & - & - & - & $1 \times 10^{-3}$ & $0.1 \times 10^{-3}$ & $1 \times 10^{-3}$ \\
\hline
\end{tabular}


the aqueous-methanolic fraction (aq-meth). The aqueous-aqueous fraction (aq-aq) included the above mentioned sugars which were determined through derivatization procedure and GC-MS analysis.

The aqueous-methanolic fraction (aq-meth) was subjected to MPLC (RP-18 Silica Merck) eluted with $\mathrm{H}_{2} \mathrm{O}$ / $\mathrm{MeOH}$ step gradient to afford 6 fractions (C1-C6). From these fractions through column chromatography on Sephadex LH-20 (Pharmacia) eluted with $\mathrm{H}_{2} \mathrm{O} / \mathrm{MeOH}$ step gradient, and the following flavonoids have been isolated: kaempferol 3-O-rhamnoside (1, $2.7 \mathrm{mg})$, a mixture of quercetin 3-O-glucoside (2) and quercetin 3-Ogalactoside (3) (2.9 mg), quercetin 3-O-rhamnoside (4, $4.3 \mathrm{mg})$, isorhamnetin 3-O-xylosyl(1-6)glucoside $(5,2.0$ $\mathrm{mg}), 7$-O-methylherbacetin 3-O-sophoroside $(\mathbf{6}, 19.5$ $\mathrm{mg}$ ), and 7-O-methylherbacetin 3-O-glucosyl-8-O-galactoside $(7,1.9 \mathrm{mg}$ ) (Figure 1). Their structures have been established by NMR spectra and by comparison with the literature. ${ }^{1} \mathrm{H}$ NMR $(400 \mathrm{MHz})$ and ${ }^{13} \mathrm{C}$ NMR $(50$ $\mathrm{MHz}$ ) data were recorded on a Bruker DRX-400 spectrometer and on a Bruker AC200 spectrometer, respectively (using TMS as an internal standard). COSY, HMQC, HMBC and NOESY (mixing time $950 \mathrm{~ms}$ ) NMR data were performed using standard Bruker micro programs.

\section{Derivatization and GC/MS Analysis of pollen extracts}

The $\mathrm{MeOH}$ extract was derivatized prior to analysis. For this purpose, about $5 \mathrm{mg}$ of the residue was mixed with $50 \mu \mathrm{L}$ of dry pyridine and $75 \mu \mathrm{L}$ of bis(trimethylsilyl)trifluoracetamide (BSTFA) and heated at $80^{\circ} \mathrm{C}$ for $20 \mathrm{~min}$. The silylated extract was analyzed by GC-MS. An aliquot $(2 \mu \mathrm{L})$ of the derivatized sample was injected into the gas chromatograph at a split ratio 1:20.

The GC-MS analysis was performed using a Hewlett Packard 6890 series II gas chromatograph equipped with an HP-5 capillary column $(30 \mathrm{~m}, 0.25 \mathrm{~mm}$ i.d., 0.25 $\mu \mathrm{m}$ film thickness) and a mass spectrometer 5973 of the same company which was operated on EI mode. Helium was the carrier gas at a flow rate of $1 \mathrm{ml} / \mathrm{min}$. The injector was operated at $200^{\circ} \mathrm{C}$ and the oven temperature was programmed from 100 to $300^{\circ} \mathrm{C}$ at a rate of $5^{\circ}$ $\mathrm{C} / \mathrm{min}$.

The identification of the compounds was based on comparison of their retention indices (RI), retention times (RT) and mass spectra with those from Wiley libraries spectra and literature data.

\section{Antimicrobial activity}

Antimicrobial activity of the extracts and the isolated compounds was determined using the agar dilution technique [31]. For all assays, stock solutions of the tested extracts were prepared at $10 \mathrm{mg} / \mathrm{ml}$. Serial dilutions of the stock solutions in broth medium $(100 \mu \mathrm{l}$ of Müller-Hinton broth or on Sabouraud broth for the fungi) were prepared in a microtiter plate (96 wells). Then $1 \mu \mathrm{l}$ of the microbial suspension (the inoculum, in sterile distilled water) was added to each well. For each strain, the growth conditions and the sterility of the medium were checked and the plates were incubated as referred above. MICs were determined as the lowest concentrations preventing visible growth. Standard antibiotic netilmicin (at concentrations $4-88 \mu \mathrm{g} / \mathrm{ml}$ ) was used in order to control the sensitivity of the tested bacteria, while 5-flucytocine and itraconazole (at concentrations $0.5-25 \mu \mathrm{g} / \mathrm{ml}$ ) as control against the tested fungi. For each experiment, any pure solvent used was also applied as blind control. The experiments were repeated three times and the results were expressed as average values.

A panel of microorganisms, including two Gram positive bacteria: Staphylococcus aureus (ATCC 25923) and S. epidermidis (ATCC 12228); four Gram negative bacteria: Escherichia coli (ATCC 25922), Enterobacter cloacae (ATCC 13047), Klebsiella pneumoniae (ATCC 13883) and Pseudomonas aeruginosa (ATCC 227853); as well as three pathogenic fungi: Candida albicans (ATCC 10231), C. tropicalis (ATCC 13801) and C. glabrata (ATCC 28838) were used. Standard antibiotics netilmicin and amphotericin B were used in order to control the tested bacteria and fungi.

\section{Measurement of proteasome parameters \\ Reagents and antibodies}

LLVY-AMC, MG132, as well as primary proteasomal antibodies against $\beta_{2}$ (PW8145; $\left.28 \mathrm{kDa}\right)$ and $\beta_{5}$ (PW8895; $23 \mathrm{kDa}$ ) subunits were purchased from BIOMOL. Primary antibody against GAPDH (sc25778; 37 $\mathrm{kDa}$ ) and secondary antibodies were purchased from Santa Cruz Biotechnology.

\section{Cell lines and culture conditions}

HFL-1 human embryonic fibroblasts were obtained by the European Collection of Cell Cultures and were maintained in Dulbecco's modified Eagle's medium (DMEM; Invitrogen) supplemented with $10 \%$ fetal bovine serum (v/v; Invitrogen), $2 \mathrm{mM}$ glutamine, and $1 \%$ non-essential amino-acids (complete medium). HFL1 cells were subcultured at $37^{\circ} \mathrm{C}, 5 \% \mathrm{CO}_{2}$ and $95 \%$ humidity, were fed approximately $16 \mathrm{~h}$ prior to each assay and cell number was determined in duplicates using a Coulter $\mathrm{Z}_{2}$ counter (Beckman Coulter). HFL-1 cells were subcultured when they reached confluence at a split ratio 1:2.

\section{Proteasome peptidase assays}

CT-L proteasome activity was assayed in crude extracts with the hydrolysis of fluorogenic peptide LLVY-AMC at $37^{\circ} \mathrm{C}$ for $30 \mathrm{~min}$, as described previously [32]. Proteasome activity was determined as the difference between the total activity of crude extracts and the remaining 
activity in the presence of $20 \mu \mathrm{M}$ MG132. Fluorescence was measured using a VersaFluorTM fluorescence spectrophotometer (BioRad). Protein concentrations were determined using the Bradford method with bovine serum albumin (BSA) as standard.

\section{Immunoblot analysis}

Cells were harvested at indicated time points, lysed in reducing Laemmli buffer and proteins were fractionated by sodium dodecyl sulfate-polyacrylamide gel electrophoresis (SDS-PAGE) according to standard procedures [33]. Proteins were then transferred to nitrocellulose membranes for probing with appropriate antibodies. Secondary antibodies conjugated with horseradish peroxidase and enhanced chemiluminescence was used to detect the bound primary antibodies. Equal protein loading was verified by reprobing each membrane with a GAPDH antibody.

\section{Statistical analysis}

Statistics were performed by using Microsoft Excel software. Statistical significance was evaluated using the one-way analysis of variance (ANOVA). Results at $p<$ 0.05 or $p<0.01$ are denoted in graphs by a single (*) or double $(* *)$ asterisk, respectively.

\section{Antioxidant activity by the DPPH test Chemicals and Standards}

DPPH: (2,2-diphenyl-1-picryhydrazyl radical), PCA (protocatechuic acid) and Folin-Ciocalteau's phenol reagent were obtained from Sigma Chemicals Company Ltd. (St. Louis, USA) and sodium carbonate $\left(\mathrm{Na}_{2} \mathrm{CO}_{3}\right)$ was from Merck Ltd, Darmstadt, Germany.

\section{DPPH assay}

Total antioxidant activity of the methanolic fraction of the aqueous extract and the standard antioxidant BHT was determined by estimation of the \% radical scavenging activity by the DPPH test [34]. An aliquot $(50 \mu \mathrm{L})$ of the extract or the antioxidant standard solution in methanol, containing increasing amounts of antioxidants, was mixed with $1 \mathrm{~mL}$ of DPPH solution $(70 \mu \mathrm{M}$ in methanol). The kinetics of the decrease of the absorption at $515 \mathrm{~nm}$ was recorded in a glass cuvette $(1 \mathrm{~cm}$ long), after the addition of the antioxidant solution against a methanol blank, until the reaction reached a plateau and the percentage of $\mathrm{DPPH}^{-}$remaining at the steady state was determined as a function of antioxidant concentration. The latter was used to determine the efficient concentration $\left(\mathrm{EC}_{50}\right)$, that is, the concentration of pollen extract ( $\mathrm{mg}$ of extract dry matter $/ \mathrm{mL}$ ) necessary to decrease the initial [DPPH'] by $50 \%$. The blank sample consisted of methanol $(1 \mathrm{~mL})$ where $50 \mu \mathrm{L}$ of the corresponding extract were added.

\section{Determination of Total Phenolics}

The concentration of total polyphenols in the methanolic fraction of the pollen aqueous extract was estimated with the Folin-Ciocalteau reagent [35]. The procedure consisted of dilution of an aliquot of the extract (up to $100 \mu \mathrm{L}$ ) with water to $600 \mu \mathrm{L}$ and addition of $60 \mu \mathrm{L}$ of Folin-Ciocalteau reagent. After $3 \mathrm{~min}, 120 \mu \mathrm{L}$ of saturated (35\%) $\mathrm{Na}_{2} \mathrm{CO}_{3}$ solution was added. The content was mixed and diluted to $1.2 \mathrm{~mL}$ with water. The absorbance was measured after 1 hour at $725 \mathrm{~nm}$ against a reagent blank. Protocatechuic acid (0-16 $\mu \mathrm{g} / 1.2 \mathrm{~mL})$ served as a standard for preparing the calibration curve.

\section{Statistical analysis}

Results are expressed as the means \pm SD of three replicates.

\section{Conclusion}

The Greek pollen is very rich in flavonoids and phenolic acids as it has been shown in this study through the total phenolics as well as through the isolations procedure. This composition indicates the observed free radical scavenging activity and the effects of pollen on human fibroblasts and provides new insights towards enhancement of cellular antioxidant mechanisms by natural products as bee-pollen. Moreover, the interesting antimicrobial profile especially against Gram positive strains together with the other beneficial effects of Greek pollen, which is successfully introduced as a food supplement and can be easily up-taken through normal diet, could ameliorate the effects of ageing and wellbeing. Especially this latter mechanism, it has to be given careful consideration in the future through further scientific research.

\section{Acknowledgements}

The authors wish to thank Dr S. Karabournioti (Director of the Chemical and Analytical Laboratory of "Attiki" Bee-Culturing Company) for the pollen analysis of our pollen sample.

\section{Author details \\ ${ }^{1}$ University of Athens, School of Pharmacy, Division of Pharmacognosy and Chemistry of Natural Products, Zografou Campus, 15771, Athens, Greece. ${ }^{2}$ National Hellenic Research Foundation, Institute of Biological Research and Biotechnology, Laboratory of Molecular and Cellular Aging, 48 Vas. Constantinou Av., 11635, Athens, Greece. ${ }^{3}$ National Hellenic Research Foundation, Institute of Biological Research and Biotechnology, 48 Vas. Constantinou Av., 11635, Athens, Greece.}

\section{Authors' contributions}

KG carried out the chemical analysis-structure elucidation and drafted the manuscript; SK carried out the measurement of proteasome activation; NA assisted to the chemical structure determination; GS carried out the determination of total phenolics and the measurement of radical scavenging activity; NC participated in the proteasome activation study; EG participated in the design of the proteasome activation study; IC conceived of the study and its design and coordination of the scientific teams, carried out the antimicrobial tests and assisted to draft the manuscript.

\section{Competing interests}

The authors declare that they have no competing interests.

Received: 11 March 2011 Accepted: 23 June 2011

Published: 23 June 2011 


\section{References}

1. Leblanc BW, Davis OK, Boue S, Delucca A, Deeby T: Antioxidant activity of Sonoran Desert bee pollen. Food Chem 2009, 115:1299-1305.

2. Hanssen M: The healing power of pollen-and other products from the beehive, Propolis, Royal Jelly, Honey Wellingborough: Thorsons Publishers Ltd; 1979.

3. Almeida-Muradian LB, Pamplona LC, Coimbra S, Barth OM: Chemical composition and botanical evaluation of dried bee pollen pellets. J Food Comp Anal 2005, 18:105-111.

4. Human $\mathrm{H}$, Nicolson SW: Nutritional content of fresh, bee-collected and stored pollen of Aloe greatheadii var. davyana (Asphodelaceae). Phytochemistry 2006, 67:1486-1492.

5. Campos MG, Markham KR, Mitchell KA, Proenca da Cunha A: An approach to the characterization of bee pollens via their flavonoid/phenolic profiles. Phytochem Anal 1997, 8:181-185.

6. Markham KR, Campos MG: 7 and 8-O-methylherbacetin-3-O-sophorosides from bee pollen and some structure/activity observations. Phytochemistry 1996, 43:763-767.

7. Campos MG, Webby RF, Markham KR, Mitchell KA, Cunha AP: Age-induced diminution of free radical scavenging capacity in bee pollens and the contribution of constituent flavonoids. J Agric Food Chem 2003, 51:742-745.

8. Almaraz-Abarca N, Campos MG, Avila-Reyes JA, Naranjo-Jimenez N, HerreraCorral J, Gonzalez-Valdez LS: Variability of antioxidant activity among honeybee-collected pollen of different botanical origin. Interciencia 2004, 29:574-578.

9. Carpes ST, Mourao GB, Alencar SM, Masson ML: Chemical composition and free radical scavenging activity of Apis mellifera bee pollen from Southern Brazil. Brazilian J Food Technol 2009, 12:220-229.

10. Davies KJ: Intracellular proteolytic systems may function as secondary antioxidant defenses: a hypothesis. Free Radical Biol Med 1986, 2:155-173.

11. Friguet B, Bulteau AL, Chondrogianni N, Conconi M, Petropoulos I: Protein degradation by the proteasome and its implications in aging. Ann N Y Acad Sci 2000, 908:143-154.

12. Chondrogianni N, Gonos ES: Proteasome dysfunction in mammalian aging: steps and factors involved. Exp Gerontol 2005, 40:931-938.

13. Wiermann R: Phenylpropanoid metabolism by pollen. I. Survey of flavonoid components isolated from gymnosperms and angiosperms. Ber Dent Bot Ges 1968, 81:3-16.

14. Meurer B, Wiermann R, Strack D: Phenylpropanoid Patterns in Fagales Pollen and Theirphylogenetic Relevance. Phytochemistry 1988, 27:823-828.

15. Wollenweber $E$, Wiermann R: On the pigmentation of the pollen of Nothofagus antarctica (Forst.) Oerst. (Fagaceae). Z Naturforsch 1979, 34c:1289-1291.

16. Serra Bonvehí J, Soliva Torrentó M, Centelles Lorente E: Evaluation of Polyphenolic and Flavonoid Compounds in Honeybee-Collected Pollen Produced in Spain. J Agric Food Chem 2001, 49:1848-1853.

17. Tomas-Lorente F, Garcia-Grau MM, Nieto JL, Tomas-Barberan FA: Flavonoids from Cistus ladanifer bee pollen. Phytochemistry 1992, 31:2027-2029.

18. Ferreres F, Tomas-Barberan FA, Tomas-Lorente F, Nieto JL, Rumbero A Olias JM: 8-methoxykaempferol 3-sophoroside, a yellow pigment from almond pollen. Phytochemistry 1989, 28:1901-1903.

19. Ferreres F, Ortiz A, Silva C, Garcia-Viquera C, Tomas-Barberan FA, TomasLorente F: Flavonoids of "LaAlcarria" honey. A study of their botanical origin. Z Lebensm Unters Forsch 1992, 194:139-143.

20. Manning R: Fatty acids in pollen: a review of their importance for honeybees. Bee World 2001, 82:60-75.

21. Markowicz Bastos DH, Barth OM, Rocha Cl, Da Silva Cunha IB, De Oliveira Carvalho P, Torres EA, Michelan M: Fatty acid composition and palynological analysis of bee (Apis) pollen loads in the states of Sao Paulo and Minas Gerais. Brazil J Apicult Res 2004, 43:35-39.

22. Farag RS, Youseff AM, Ewies MA, Hallabo SAS: Longchain fatty acids of six pollens collected by honeybees in Egypt. J Apicult Res 1978, 17:100-104.

23. Manning R, Harvey M: Fatty acids in honeybee-collected pollens from six endemic Western Australian eucalypts and the possible significance to the Western Australian beekeeping industry. Aust J Exp Agric 2002, 42:217-223.

24. Qian WL, Khan Z, Watson DG, Fearnley J: Analysis of sugars in bee pollen and propolis by ligand exchange chromatography in combination with pulsed amperometric detection and mass spectrometry. J Food Comp Anal 2008, 21:78-83.
25. Huang L, Ho P, Chen $\mathrm{CH}$ : Activation and inhibition of the proteasome by betulinic acid and its derivatives. FEBS Letters 2007, 581:4955-4959.

26. Chondrogianni N, Kapeta S, Chinou I, Vassilatou K, Papassideri I, Gonos ES: Anti-ageing and rejuvenating effects of quercetin. Exp Geronto/ 2010, 45:763-771.

27. Hanssen M: E for Additives: The Complete E Number Guide London: Thorsons Publ. Ltd; 2002.

28. Loizzo MR, Statti GA, Tundis R, Conforti F, Ando S, Menichini F: Antimicrobial activity and cytotoxicity of Cirsium tenoreanum. Fitoterapia 2004, 75:577-580

29. Basim E, Basim H, Özcan M: Antibacterial activities of Turkish pollen and propolis extracts against plant bacterial pathogens. J Food Engin 2006 77:992-996.

30. Erkmen O, Özcan M: Antibacterial effects of Turkish propolis, pollen and laurel on the spoilage and pathogenic food-related microorganisms. $J$ Med Food 2008, 11:587-592

31. Melliou E, Chinou I: Chemical analysis and antimicrobial activity of Greek propolis constituents. Planta Med 2004, 70:515-519.

32. Chondrogianni N, Petropoulos I, Franceschi C, Friguet B, Gonos ES: Fibroblast cultures from healthy centenarians have an active proteasome. Exp Gerontol 2000, 35:721-728

33. Harlow E, Lane D: Using antibodies: a laboratory manual Cold Spring Harbour Laboratory Press, Cold Spring Harbour; 1999.

34. Nenadis N, Tsimidou M: Observations on the Estimation of Scavenging Activity of Phenolic Compounds Using Rapid 1,1-Diphenyl-2picrylhydrazyl (DPPH) Tests. J Am Oil Chem Soc 2002, 79:1191-1195.

35. Gutfinger T: Polyphenols in olive oils. J Am Oil Chem Soc 1981, 58:966-968.

\section{doi:10.1186/1752-153X-5-33}

Cite this article as: Graikou et al: Chemical analysis of Greek pollen Antioxidant, antimicrobial and proteasome activation properties. Chemistry Central Journal 2011 5:33.

\section{Publish with ChemistryCentral and every scientist can read your work free of charge \\ "Open access provides opportunities to our colleagues in other parts of the globe, by allowing anyone to view the content free of charge." W. Jeffery Hurst, The Hershey Company.}

- available free of charge to the entire scientific community

- peer reviewed and published immediately upon acceptance

- cited in PubMed and archived on PubMed Central

- yours - you keep the copyright

Submit your manuscript here:

http://www.chemistrycentral.com/manuscript/<smiles>c1ccccc1</smiles>

ChemistryCentral 